\title{
Evaluating Fractures in Rocks from Geothermal Reservoirs Using Resistivity at Different
}

\section{Frequencies}

\author{
Kewen $\mathrm{Li}^{1}$, Baozhi Pan ${ }^{2,1}$, Roland Horne ${ }^{1}$ \\ ${ }^{1}$ Stanford Geothermal Program, Stanford University, 367 Panama St., Stanford, CA94305, USA \\ ${ }^{2}$ Jilin University
}

Corresponding Author: E-mail: kewenli@stanford.edu

\begin{abstract}
One of the key issues to a successful EGS (Enhanced or engineered Geothermal System) is the creation of a great density of fractures. The detection and characterization of the created fractures is crucial in evaluating the geothermal energy resources in such EGS projects as well as in reservoirs for $\mathrm{CO}_{2}$ sequestration and storage. Methods to evaluate the fractures after stimulations are few, and limited in application. To this end, an approach to detecting and evaluating the fractures using resistivity data measured at different frequencies was developed in this study. The effects of fractures on resistivity measurements at different frequencies have been investigated as a function of water saturation in rocks with different porosity, permeability and lithology. Different rocks (Berea sandstone, and greywacke from The Geysers geothermal reservoir) were used in this study. The permeability of the samples ranged from 0.5 to over $1000 \mathrm{md}$ for the matrix. The frequency ranged from 100 to $100,000 \mathrm{~Hz}$. It was found that the effect of frequency on resistivity is different in rocks with and without fractures, especially in the range of low water saturation. The validity of the Archie equation depends on the existence of fractures, the frequency, and the range of water saturation. The relationship between resistivity and water saturation did not follow the Archie equation at low water saturation in some rocks with fractures. Models for characterizing different types of rocks with specific fracture patterns have been established using the resistivity data measured at different frequencies and different water saturations.
\end{abstract}

Keywords: fracture characterization, Enhanced Geothermal System, resistivity, frequency dependence, geothermal reservoirs

\section{Introduction}

The concept of Enhanced Geothermal Systems (EGS) has been investigated widely (for example, Nalla, et al., 2004; Nalla and Shook, 2004; Wang, et al., 2009 and 2010, Hettkamp et al., 2004; Sanjuan, et al., 2006). One of the key issues to a successful EGS project is the creation of a great density of fractures (Rutqvist, et al., 2015; Jiang, et al., 2014). The detection and characterization of the created and natural fractures is crucial in evaluating and developing the geothermal energy resources in such EGS projects. This is also true in other types of fractured reservoirs such as those for oil recovery and for $\mathrm{CO}_{2}$ sequestration or storage. The reason is that the recoverable 
resources or reserves are proportional to the fluid production rates in the wells. The hydraulically or chemically created fractures provide conductive paths to the stored fluids and energy in the reservoir rocks to the wellbore. So the well production rates depend on the properties of the fractures and their network in the subsurface.

There are a few existing methods to evaluate the fractures after stimulation. One of these approaches is analytical modeling using production data. Several mathematical models have been reported to characterize the properties of the hydraulic fractures near the wellbore using production data (Cramer, 2003; Soliman et al., 2005; Crafton and Gunderson, 2006). However the evaluation of the fracture properties is just the average of the fractures, which would be a limitation for analysis of an EGS configuration.

Aguilera (1974) demonstrated a means of detecting and analyzing fractured systems from well logs. It appears from the cases considered that the porosity exponent $m$ is an adequate criterion to detect such a fractured system. Pérez-Rosales et al. (2000) reported a new formulation for determining formation resistivity factors of fractured porous media and showed a model that could fit some of the experimental data.

The frequency dependence of electrical and dielectric properties of rock partially saturated with water has been reported by many researchers (Knight and Nur, 1987; Adisoemarta and Morriss, 1992; Börner, 1997; Bona et al. 2001; Haugland, 2005). Knight and Nur (1987) collected impedance data for eight sandstones at various levels of water saturation in the frequency range of $5 \mathrm{~Hz}$ to $4 \mathrm{MHz}$. They found that the real component of dielectric constant of all samples at all levels of saturation showed a clear power-law dependence upon frequency. Comparing the data from the eight sandstone samples at a water saturation of 36\%, the magnitude of the frequency dependence was proportional to the surface area-to-volume ratio of the pore space of the sandstones.

Adisoemarta and Morriss (1992) investigated the electrical properties of swelling shales across a wide frequency range from $10 \mathrm{~Hz}$ to 1.3 GHz. They found that the resistivity of different types of shales decreased with the increase in frequency from $10 \mathrm{~Hz}$ to about 10 $\mathrm{KHz}$ but stayed almost constant when the frequency was above $10 \mathrm{KHz}$. The experimental data presented by Adisoemarta and Morriss (1992) also demonstrated that the effect of frequency on the resistivity was more significant at lower water saturations than at higher water saturations.

In a recent study (Sandler et al, 2009), the resistivity in a sandstone core sample without fractures was measured at three different frequencies of 100,1000 , and $10,000 \mathrm{~Hz}$ to investigate the effect of frequency on the measurement of resistivity. In this case, the measured resistivity did not change significantly with frequency.

The relationship between the resistivity index and the water saturation follows Archie's law (Archie, 1942) in many rocks. The Archie model is expressed as:

$$
I=\frac{R_{t}}{R_{0}}=S_{w}{ }^{-n}
$$


where $I$ is the resistivity index, $R_{o}$ is the resistivity of rock at a water saturation of $100 \%, R_{t}$ is the resistivity at a specific water saturation of $S_{w}, n$ is the saturation exponent.

Sandler et al. (2009) also measured the resistivity in a sandstone core sample with one visual fracture at the same three frequencies of 100,1000 , and 10,000 Hz. It was found that there was almost no effect of frequency on the resistivity index in this core when the water saturation was greater than about $25 \%$. However the resistivity index increased with the decrease in frequency when the water saturation was less than about $25 \%$. The effect of frequency on the resistivity index is increasingly significant as the water saturation becomes lower.

In the present study, the effects of fractures and frequencies on resistivity as a function of water saturation have been investigated in rocks with different porosity, permeability, and lithology. Models for characterizing different types of rocks with specific fracture patterns have been established using the resistivity data measured at different frequencies and different water saturations. Finally an approach to detecting and evaluating the fractures using resistivity data measured at different frequencies has been developed, which is the main purpose of this study. Using the developed method, it may be possible to estimate the mean aperture, or density of fractures after stimulations for creating fracture networks in EGS or other types of rock formations.

\section{Experimental}

\subsection{Experimental Apparatus}

An existing resistivity apparatus was modified in two aspects. Firstly the software for the data acquisition was modified using NI Labview. With the modified version of the software, the test data could be sampled from both the LCR meter at four different frequencies and the balance simultaneously. Secondly the way that the electrodes contact the core samples was modified. In the past, a stainless steel mesh was used to create the electrodes and filter paper to make a better contact between the rock and the electrodes. It was found that the stainless steel mesh eroded because of the long time contact with brine. So the eroded stainless steel mesh was replaced and fixed on a PVC plate. The resistance of the mesh from side to side and corner to corner was measured, and the measurements found to be around $3 \mathrm{ohm}$. This value could be neglected compared to the resistance of the rocks.

The main challenge encountered in this study was to establish the quantitative relationship between frequency and fracture properties. The experimental data during the early period of this study did not demonstrate significant differences between one and two artificial fractures. It was speculated that the reason could be that the values of the stress applied to the core samples in different tests were not the same. For this reason, the apparatus was modified by installing a strain sensor between the core sample and the end plate holding the core samples. This allowed the device to impose exactly the same force on the electrodes in each experiment. A schematic of the modified apparatus is shown in Figure 1a.

Also added was a module to provide a convenient means of completing the Wheatstone Bridge circuit used for the strain gauge measurement (see Figure 1a). The strain gauge system was then installed (see Figure 1b). 
The measurements under the same tightening stress could be conducted using the modified apparatus.

Another modification made to the apparatus was to the on-line weighing method for determining the water saturation. Very fine copper cables with a diameter of $0.50 \mathrm{~mm}$ were used to connect to the RCL meter for measuring the resistivity of the core sample on-line (without taking the core sample off the balance). It was found that the weighing system was much faster and easier to stabilize after replacing the old stiffer cables with these fine wires. The previous difficulty in weighing the core sample (in which the movement of the wires caused the reading of the balance changes with time even though the weight of the core does not change) was finally solved.

\subsection{Rock Samples}

In this study, six rock samples were used, including sandstone, granite, and limestone with or without fractures (both natural and artificial fractures). Figure 2 shows all of the core samples used in this study.

The dimensions and the physical properties of the cylindrical core samples are listed in Table1 and are analyzed as follows in more detail.

\subsubsection{Single Homogeneous Rock samples}

Four homogeneous (without fractures inside the rock) sandstone samples, I1-1, \#5, s1, and s2, were used. Sample I1-1 (see Fig. 2a) had a porosity of $18.98 \%$. Sample \#5 (Fig. 2b) had a porosity of 22.04\%. Samples s1 and s2 (see Fig. 2c) had a porosity of 20.64 and $20.56 \%$ respectively. Core samples I1-1 and s1 were utilized to verify that there is no effect of frequency on resistivity in homogeneous rocks. Sandstone samples s1 and s2 were used to make fractures with different apertures by putting the two sample against each other. Note that sample I1-1 was natural Berea sandstone without clay removed by burning at a high temperature. Samples s1 and s2 were Berea sandstone but burned at a temperature of about $600^{\circ} \mathrm{C}$ in order to remove the clay.

\section{$\underline{\text { 2.2.2 Rocks with different fracture apertures }}$}

It was an essential step to make rock samples with a single fracture but with adjustable fracture aperture, to find the relationship between fracture aperture and the effect of frequency on resistivity. As stated previously, the two fired Berea sandstone samples (s1 and s2) were put against each other and tightened using clamps to construct a rock sample with one fracture. Adjustment of the fracture aperture was achieved by putting plastic shims of different thickness $(0.08,0.16,0.24 \mathrm{~mm})$ in between samples $\mathrm{s} 1$ and $\mathrm{s} 2$. The minimum fracture aperture, estimated at about $0.04 \mathrm{~mm}$, was obtained in the case where no plastic shims were put in between the samples. In total, four rock samples with a single fracture but four different apertures $(0.04,0.08,0.16,0.24 \mathrm{~mm})$ were constructed. It should be noted that the fractures made in this way were artificial.

\subsubsection{Rocks with natural fractures}

In addition to the artificially-made fractures described in last section, rocks with naturally occurring fractures were also used. Graywacke rock samples, G-1 and L-1, from The Geysers geothermal field were used in this study. Samples G-1 and L-1 had very small 
values of porosity, 1.03 and $3.54 \%$ respectively. Some microfractures could be seen on the surface of these two rock samples (see Figs.

$1172 \mathrm{~d}$ and $2 \mathrm{e})$.

\subsection{Experimental Procedures}

The rock samples had varying degree of fracturing, from unfractured sandstones to fractured geothermal greywacke, with some samples fractured artificially so that the effect of known fracture apertures could be evaluated. Electrodes were constructed by soldering wires to two patches of stainless steel mesh. The wires were connected to an RCL meter (Quad Tech 1715 or IET labs) and on the other end clamped to either side of the rock via a hand clamp. This was done alternatively with and without a piece of filter paper clamped between the rock end and the stainless steel electrodes and soaked in the same $1 \%$ brine solution $(\mathrm{NaCl})$ in which the rocks were saturated. There was no noticeable difference between the experiments with and without filter paper in some of the cases. This entire apparatus was placed upon a rubber sheet on top of a balance with a reading accuracy of $0.01 \mathrm{~g}$ and connected to a computer via RS-232 ports. The NI LabView software was used to gather mass, resistance, and impedance data from the core at 10-minute intervals while water was allowed to evaporate from the core at ambient temperature of about $20^{\circ} \mathrm{C}$. Measurements were taken at frequencies of 100 , 120,1000 , and $10000 \mathrm{~Hz}$. Note that the experimental data of $120 \mathrm{~Hz}$ are not included here, because these data were very close to those measured at $100 \mathrm{~Hz}$. Cores were prepared by first evacuating any air from the pore space by placing the cores in a desiccation chamber and lowering the pressure to around 100 mTorr. Brine solution prepared in a separate vacuum flask was then released into the desiccation chamber (still under vacuum) and allowed to invade the pore space overnight. Between experiments the cores were dried in a vacuum oven at $22^{\circ} \mathrm{C}$.

\section{Results}

The resistance and other electrical properties of the rock samples with and without fractures were measured at different frequencies. The results are discussed in this section.

\subsection{Single Homogeneous Rock}

Experiments in the homogeneous (without fractures) core samples were conducted in the modified apparatus with the strain gauge to make sure that the force applied between the two ends was the same every time. Figure 3 shows the results in the core sample I1-1. The values of the resistivity index in this rock are the same at different frequencies.

The resistivity data in $\mathrm{s} 1$ were also measured and confirmed that there is no effect of frequency on the resistivity index at different water saturations in this homogeneous rock either. The results are shown in Figure 4. The resistivity of the two homogeneous sandstones at different water saturation almost does not change with the frequency.

\subsection{Two Cylindrical Rocks with Different Fracture Apertures}

Two samples s1 and s2 were used to form a single fracture by placing them together with plastic shims of different thickness in between. The rock system with one layer of plastic shim is shown in Figure 5. 
The resistivity index values measured at three different frequencies in samples s1 and s2 with nothing in between are shown in Figure 6(a). Figure 6(b) shows the data of the resistivity index with one layer of plastic shim in between (fracture aperture is about $0.08 \mathrm{~mm}$ ). Figure 6(c) shows the data of the resistivity index with two layers of plastic shim (fracture aperture is about $0.16 \mathrm{~mm}$ ). Figure 6(d) shows the data of the resistivity index with three layers of plastic shim in between (fracture aperture is about $0.24 \mathrm{~mm}$ ). notable observation is the deviation point water saturation, $S_{w d}$, (where the resistivity data become different at different frequencies). $S_{w d}$ is less than $5 \%$ when the fracture aperture is less than $0.24 \mathrm{~mm}$ and is about $10 \%$ when the fracture aperture is equal to $0.24 \mathrm{~mm}$.

Figure 7(a) shows the relationships between resistivity index and water saturation at one frequency $(100 \mathrm{~Hz})$ but different fracture apertures. Figure 7(b) demonstrates the results at the frequency of $10 \mathrm{kHz}$. The red circles represent the resistivity index measured in samples s1 and s2 with nothing in between (fracture aperture is estimated about $0.04 \mathrm{~mm}$ ). The blue triangles represent the resistivity index measured with one layer of plastic shim in between (fracture aperture is about $0.08 \mathrm{~mm}$ ). The pink cross symbols represent the resistivity index measured with three layers of plastic shim in between (fracture aperture is about $0.24 \mathrm{~mm}$ ).

\subsection{Rocks with Natural Fractures}

159 Core sample G-1 was a graywacke rock from The Geysers geothermal field. Some fractures could be observed on the surface of the rock. The results of the resistivity measured at different frequencies in this rock are plotted in Figure 8 . The effect of frequency on the resistivity index is clear. Interestingly the deviation point water saturation in this low permeability rock, about $30 \%$, is much greater than that (less than 10\%) in the high permeability sandstone (see Figure 6).

Core sample L-1 was a different graywacke rock from The Geysers geothermal field. There are some obvious fractures visible on the surface of the rock. The results of the resistivity measured at different frequencies in this rock are shown in Figure 9. The effect of frequency on the resistivity index is similar to that of Core G-1, as shown in Figure 8.

One can also observe that there is a sharp increase in resistivity index during the early period of the test when water saturation is close to $100 \%$. The resistivity index vs. water saturation curves go up and down when water saturation is very small. Currently the reason has not been found for this phenomenon.

\subsection{Patterns of Resistivity Curves in Rocks with Different Types of Fractures}

Many experimental measurements of resistivity were conducted in rocks with different types of fractures. Figure 10 shows the and are described as follows. 
Pattern 1 (in rocks without fractures): the values of the resistivity index in rocks without fractures are the same at different frequencies over the entire water saturation ranging from 0 to $100 \%$. The curves of resistivity vs. water saturation at different frequencies overlap (see top left part in Figure 10).

Pattern 2 (in rocks with single artificial fractures): the resistivity index data in rocks with single fractures but different apertures are not the same at different frequencies and the curves of resistivity vs. water saturation at different frequencies do not overlap when the water saturation is less than a specific value (see the middle part in Figure 10).

Pattern 3 (in rocks with multiple or natural fractures): the resistivity indices in rocks with multiple or natural fractures are not the same either at different frequencies and the curves of resistivity vs. water saturation at different frequencies do not overlap when the water saturation is less than a specific value (see bottom right part in Figure 10).

Note that the deviation point water saturations in the three different patterns are different. This will be analyzed in more detail in the next section. The categories of rocks with fractures may be estimated using the patterns shown in Figure 10 as a template.

\subsection{Mathematical Models to Infer the Fracture Properties}

The values of resistivity index difference $(\Delta I$ : the resistivity index at $100 \mathrm{~Hz}$ minus the resistivity index at $10 \mathrm{kHz})$ at $1 \% \mathrm{water}$ saturation in the rock systems (composed of two samples s1 and s2) with single fractures but different apertures were determined according to the results shown in Figures 6. The results are plotted in Figure 11. The data from the rock systems composed of two samples s1 and s2 with three layers of plastic shim are not included in Figure 11 because the water could not be held in the fracture continuously. One can see that $\Delta I$ increases with the increase in the fracture aperture. Using the data shown in Figure 11 , the relationship between the fracture aperture and $\Delta I$ can be determined as:

$$
F_{a}=0.0191 \Delta I
$$

where $F_{a}$ is the fracture aperture in the units of $\mu \mathrm{m}$ and $\Delta I$ is the resistivity index difference at a water saturation of $1 \%$. The correlation coefficient of the fit is 0.844 . It was assumed that the values of fracture aperture and $\Delta I$ are equal to zero in the rocks without fractures.

Note that the resistivity index data did not follow the Archie equation and there was a threshold value $\left(I_{t h}\right)$ when the water saturation is close to $100 \%$. The values of resistivity index at the frequency of $10 \mathrm{kHz}$ shown in Figures 4, 6 were chosen and plotted in Figure 12.

The values of the threshold $I_{t h}$ were estimated using the data shown in Figure 12 and the results are shown in Figure 13. Using the data shown in Figure 13, the relationship between the fracture aperture and $I_{t h}$ can be determined as:

$$
F_{a}=70.675 \ln \left(I_{t h}\right)+16.397
$$

where $F_{a}$ is the fracture aperture and $I_{t h}$ is the threshold resistivity index. The correlation coefficient of the fitting in Figure 13 is 0.9822. The fracture apertures may be inferred using these mathematical models. 


\section{Discussion}

Either hydraulic or chemical stimulations have to be conducted in EGS in order to create a fracture network sufficient for fluid to flow at a rather significant rate of $80 \mathrm{~kg} / \mathrm{s}$ (Tester, et al., 2006). It is very difficult for an EGS to have such a great fluid production rate in a single well. To the best knowledge of the authors, only the Germany Landau EGS project has reached a production rate close to this value, about $76 \mathrm{~kg} / \mathrm{s}$ (Wyborn, 2011). The well production rate on the surface is dependent on the properties of fracture and its network under the subsurface in reservoirs. One challenge to this, of course, is the stimulation technology itself. Another challenge related to the creation of the fracture network in EGS is the technology and tools for detecting and characterizing the created fractures.

Although no field applications have been conducted yet, the potential of the method developed in this study may be great in practical field measurements for estimating fracture properties after hydraulic stimulations in EGS or other geothermal reservoirs. The idea and possible procedures of applying the approach to detecting fracture properties in EGS after stimulation are described as follows. During the creation of an EGS, the injection of fluids, followed by flow back and production stages, offers the opportunity to use this method in a single-well. Resistivity well logging at different frequencies could be conducted right before flowing back the liquids (mainly water in many cases) injected during stimulation to create fractures. The water saturation in the formation with the created fractures under high pressure at this time would be equal to $100 \%$. The well logging resistivity data measured at different frequencies at this point (100\% of water saturation) should be the same. That is, there is no effect of frequency on the resistivity. Measurements of the resistivity data by well logging could be continued until the end of the flow back. The liquid water saturation in the EGS after flow back may be much less than $100 \%$ because of high temperature and relatively low pressure. The well logging resistivity data measured at different frequencies at this point (water saturation less than 100\%) should not be the same. That is, there may be significant effect of frequency on the resistivity because of the fractures created by the stimulation. The fracture properties may be estimated with the resistivity data measured at different frequencies using the method developed here, although further studies are required to make the approach practical.

The approach proposed in this article may not be limited to EGS, but could also be used also in conventional geothermal reservoirs, hydrocarbon reservoirs and $\mathrm{CO}_{2}$ storage formations.

\section{Conclusions}

The following conclusions were obtained according to the theoretical and experimental studies:

1. It was confirmed that there is a significant effect of frequency on the resistivity at relatively low water saturations in rocks with artificial or natural fractures over a wide range of frequencies. On the other hand, in rocks without fractures there is almost no effect of frequency on the resistivity index over the entire range of water saturation.

2. Over a frequency range from 100 to $10,000 \mathrm{~Hz}$, the resistivity index increases with a decrease in frequency in fractured rock when the water saturation is less than a specific threshold value. 
3. Different deviation patterns have been identified in rocks with different structures of fractures (single artificial fractures with different apertures and natural fractured systems).

4. The relationships between fracture aperture and electric property parameters of the rocks have been established. Mathematical models have been developed to infer the fracture properties using the measured resistivity data.

5. It is possible to infer fracture properties in rocks using electric parameters measured at different frequencies and water saturations. This may be of great potential in practical field measurements for estimating fracture properties after hydraulic stimulations in EGS, conventional geothermal reservoirs and other types of formations such as those for hydrocarbon development and $\mathrm{CO}_{2}$ sequestration.

\section{Acknowledgement}

This research was conducted with financial support to the Stanford Geothermal Program from the US Department of Energy, Award Number DE-EE0005516, the contribution of which is gratefully acknowledged.

\section{References}

Adisoemarta, P.S. and Morriss, S.L.: "Electrical Impedance Variation with Frequency in Shales and Shaly Sands," SPE 24675, presented at the SPE Annual Technical Conference and Exhibition, 4-7 October 1992, Washington, D.C.

Aguilera, R.: “Analysis of Naturally Fractured Reservoirs from Sonic and Resistivity Logs,” JPT (November 1974), 1233-1238.

Archie, G.E.: "The electrical resistivity log as an aid in determining some reservoir characteristics," AIME Petroleum Tech. (1942), 1-8.

Archie, G.E.: "The Electrical Resistivity Log as an Aid in Determining Some Reservoir Characteristics." Trans. AIME. http://www.pe.tamu.edu/blasingame/data/z_zCourse_Archive/P663_03C/P663_03C_TAB_Ref_FormEval/SPE_Trans_1942_Archi e_Reservoir_Char_from_Resistivity_Logs.pdf.

Bona, N., Rossi, E., Capaccioli, S.: "Electrical Measurements in the $100 \mathrm{~Hz}$ to $10 \mathrm{GHz}$ Frequency Range for Efficient Rock Wettability Determination,” SPEJ (March 2001), Volume 6, Number 1, Pages 80-88.

Börner, F.D.: “Combined Complex Conductivity and Dielectric Measurements on Core Samples.” SCA Paper 9736: 7-10, 1997.

Crafton, J.W., and Gunderson, D.: "Use of Extremely High Time-Resolution Production Data to Characterize Hydraulic Fracture Properties," SPE 103591, presented at the 2006 SPE Annual Technical Conference and Exhibition held in San Antonio, Texas, U.S.A., 24-27 September 2006.

Cramer, D. D.: "Evaluating Well Performance and Completion Effectiveness in Hydraulically Fractured Low-Permeability Gas Wells," SPE 84214, presented at the SPE Annual Technical Conference and Exhibition held in Denver, Colorado, U.S.A., 5 - 8 October 2003. 
Hettkamp, T., Baumgartner, J., Baria, R., Gerard, A., Gandy, T., Michelet, S., Teza, D.: "Electricity Production from Hot Rocks.” Workshop on Geothermal Reservoir Engineering, Stanford University, Stanford, California, 2004.

Haugland, S.M.: "Frequency Dispersion Effects on LWD Propagation Resistivity Measurements," SPE 96596, presented at the SPE Annual Technical Conference and Exhibition, 9-12 October 2005, Dallas, Texas.

Jiang, F., Chen, J., Huang, W., \& Luo, L.: “A three-dimensional transient model for EGS subsurface thermo-hydraulic process.” Energy, 72, 300-310, 2014.

Knight, R.J., and A. Nur.: “The Dielectric Constant of Sandstones, 60 kHz to 4 MHz.” Geophysics 52 (5): 644-654, 1987a.

Knight, RJ, and A. Nur.: “Geometrical Effects in the Dielectric Response of Partially Saturated Sandstones.” The Log Analyst 28 (6), $1987 b$.

Nalla, G., Shook, G.M., Mines, G.L. and Bloomfield, K.: "Parametric Sensitivity Study of Operating and Design Variables in Wellbore Heat Exchangers," Workshop on Geothermal Reservoir Engineering, Stanford University, 2004.

Nalla, G. and Shook, G.M.: "Engineered Geothermal Systems Using Advanced Well Technology,” GRC Trans. V. 28 (2004).

Pérez-Rosales, C., Cruz-Hernández, J., Islas-Juárez R., and Mercado-Díaz, A.: "New Formulation for Formation Resistivity Factors of Fractured Porous Media," SPE 58991, presented at the 2000 SPE International Petroleum Conference and Exhibition in Mexico held in Villahermosa, Mexico, 1-3 February 2000.

Rutqvist, J., Dobson, P. F., Garcia, J., Hartline, C., Jeanne, P., Oldenburg, C. M., Vasco, D. W., and Walters, M.: "The Northwest Geysers EGS demonstration project, California: Pre-stimulation modeling and interpretation of the stimulation." Mathematical Geosciences 47, no. 1 (2015): 3-29.

Sandler, J., Li, Y., Horne, R. N., Li, K.: "Effects of Fracture and Frequency on Resistivity in Different Rocks," SPE 119872 , to be presented at the 2009 SPE EUROPEC/EAGE Annual Conference and Exhibition held in Amsterdam, The Netherlands, 8-11 June 2009.

Sanjuan, B., Pinault, J., Rose, P., Grard, A., Brach, M, Braibant, G., Crouzet, C., Foucher, J., Gautier, A., Touzelet, S.: “Tracer Testing of the Geothermal Heat Exchanger at Soultz-sous-Forets (France) Between 2000 and 2005," Geothermics, 35, 622-653, 2006.

Soliman, M. Y., Craig, D., Bartko, K., Rahim, Z., and Adams, D.: "Post-Closure Analysis to Determine Formation Permeability, Reservoir Pressure, Residual Fracture Properties," SPE 93419, presented at the 14th SPE Middle East Oil \& Gas Show and Conference held in Bahrain International Exhibition Centre, Bahrain, 12-15 March 2005.

Tester, Jefferson W., Brian J. Anderson, A. S. Batchelor, D. D. Blackwell, Ronald DiPippo, E. M. Drake, J. Garnish et al. "The future of geothermal energy." Impact of Enhanced Geothermal Systems (EGS) on the United States in the 21st Century, Massachusetts 
Wang, Z., McClure, M.W. and Horne, R.N.: “A Single-Well EGS Configuration Using a Thermosiphon,” Workshop on Geothermal Reservoir Engineering, Stanford University, Stanford, California, 2009.

Wang, Z., McClure, M.W. and Horne, R.N.: "Modeling Study of Single-Well EGS Configurations," Proceedings of World Geothermal

Table 1: The dimensions and the physical properties of the cylindrical core samples

\begin{tabular}{|c|c|c|c|c|c|c|}
\hline Sample Types & Sample No. & $\mathrm{L}(\mathrm{mm})$ & $\mathrm{D}(\mathrm{mm})$ & Dry weight (g) & Wet weight (g) & Porosity (\%) \\
\hline \multirow{4}{*}{ Homogeneous } & I1-1 & 64.0 & 37.92 & 152.23 & 166.30 & 18.98 \\
\hline & $\# 5$ & 50.8 & $50.8 \times 50.8$ & - & - & 22.04 \\
\hline & S-1 & 27.12 & 26.517 & 31.040 & 34.130 & 20.64 \\
\hline & S-2 & 24.943 & 26.043 & 27.990 & 30.720 & 20.56 \\
\hline \multirow{2}{*}{ Heterogeneous } & G-1 & 83.02 & 50.63 & 449.40 & 451.13 & 1.03 \\
\hline & L-1 & 51.82 & 37.33 & 147.75 & 149.76 & 3.54 \\
\hline
\end{tabular}


301

302

303

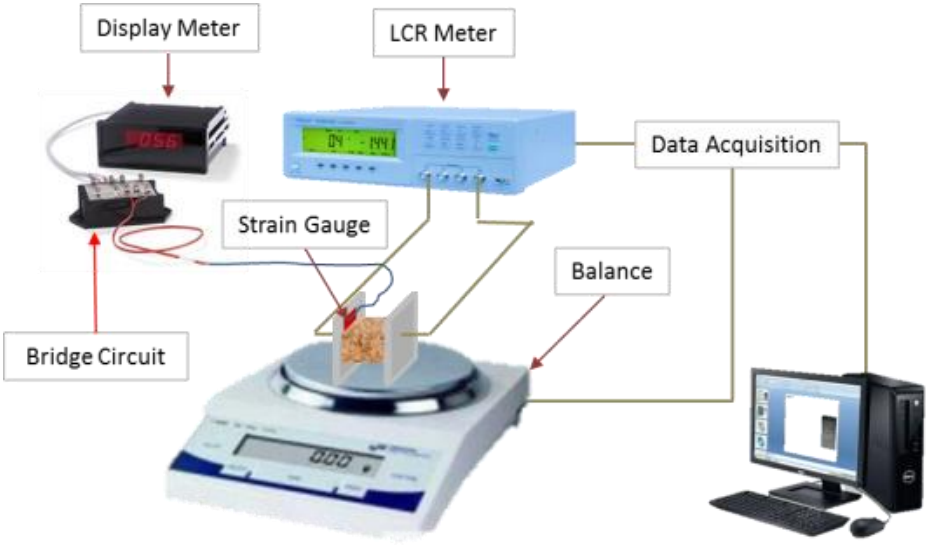

(a) Schematic of the modified apparatus with strain gauge installed

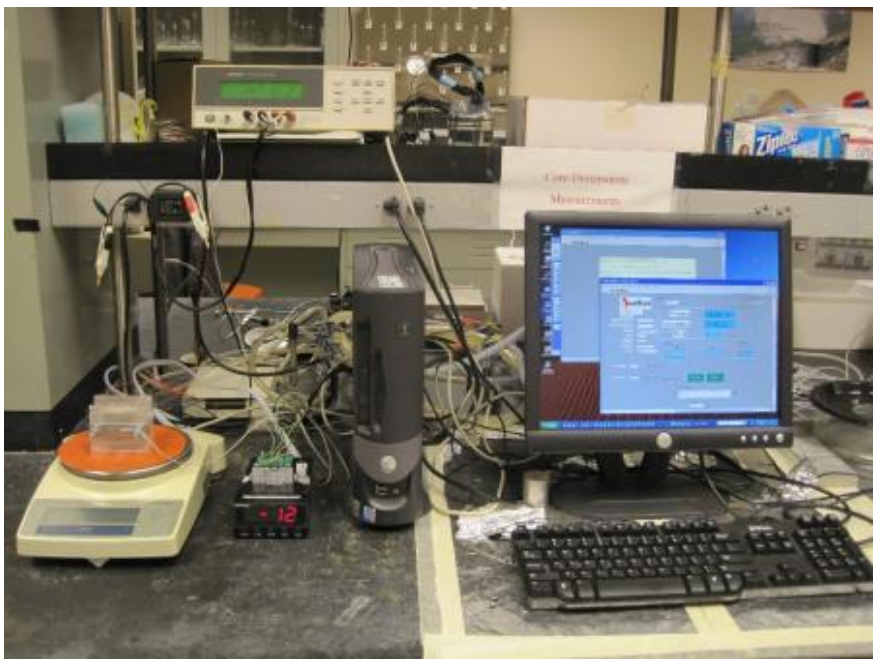

(b) Photo of the modified apparatus with strain gauge installed

Figure 1: The modified apparatus including the strain gauge to apply the same stress to the core samples.

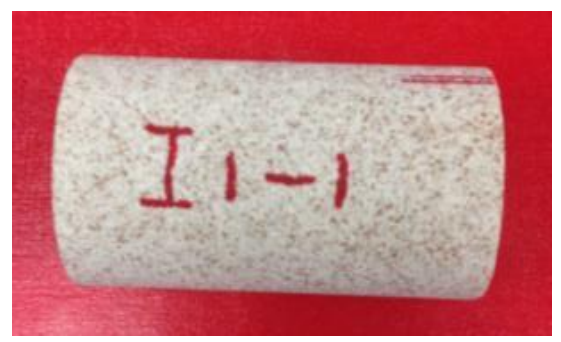


310

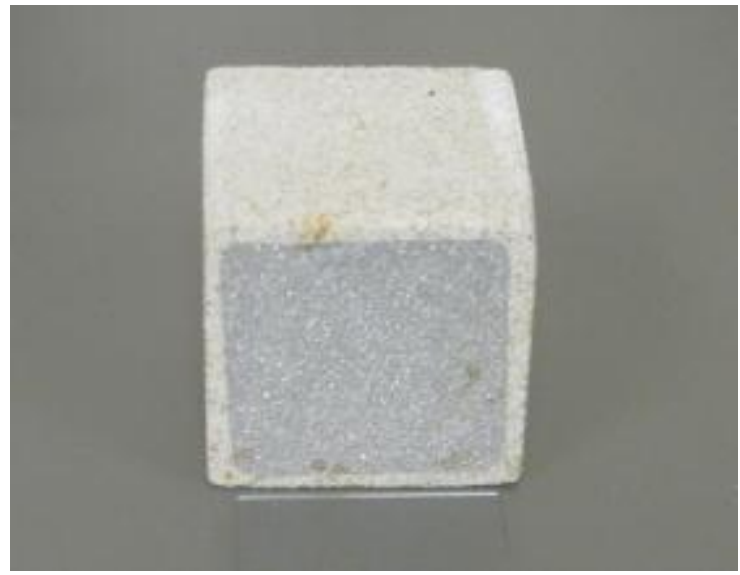

(b) Homogeneous rock sample (cubic Berea sandstone) \#5

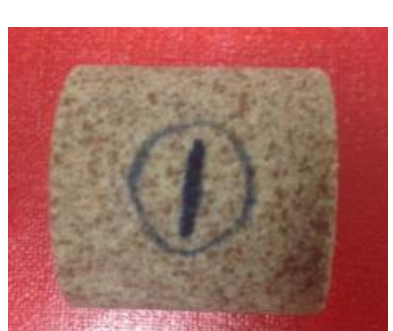

sample s1

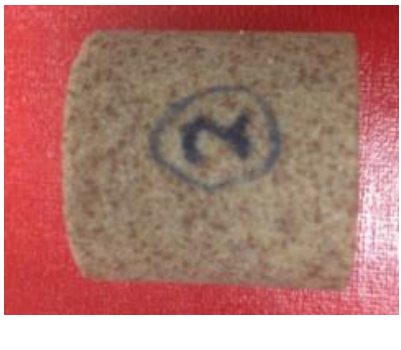

sample 52 such as porosity and permeability).

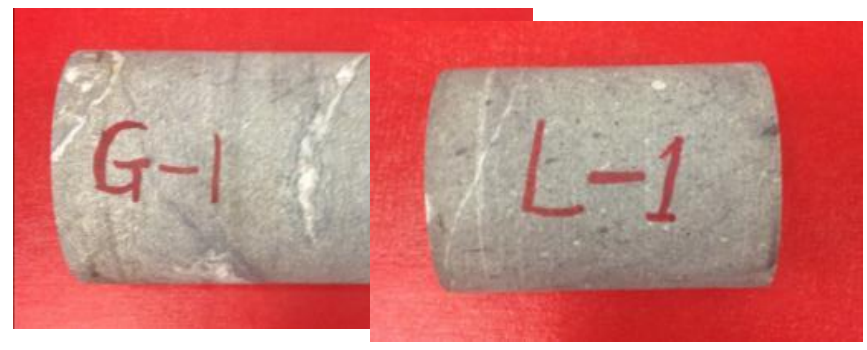




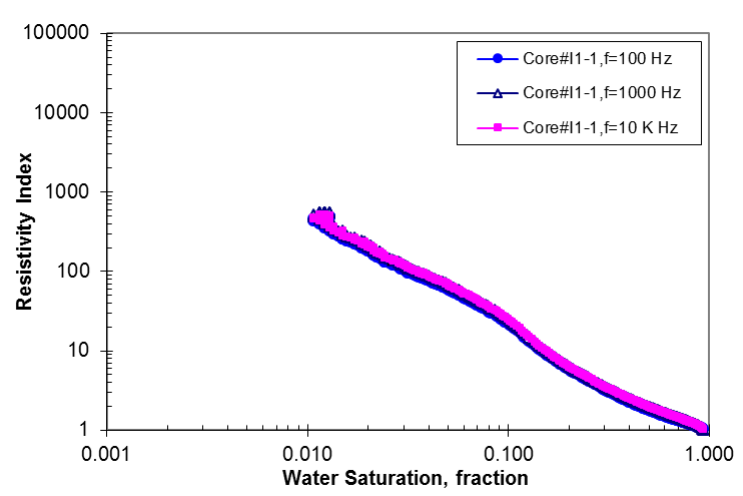

Figure 3: Resistivity Index vs. water saturation

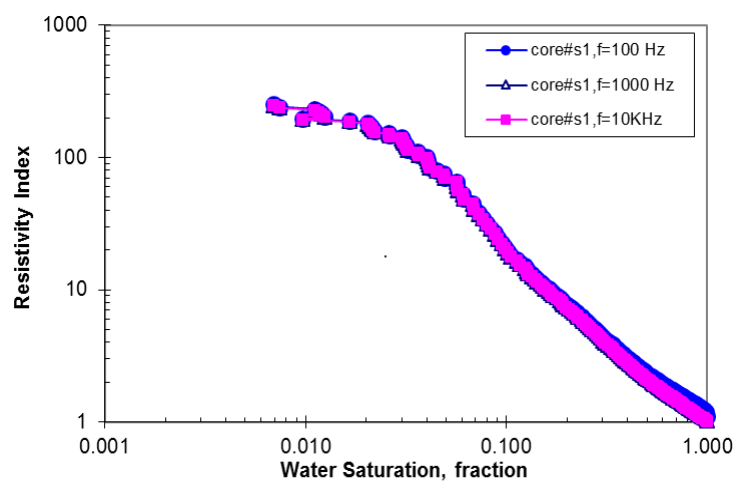

Figure 4: Resistivity Index vs. water saturation

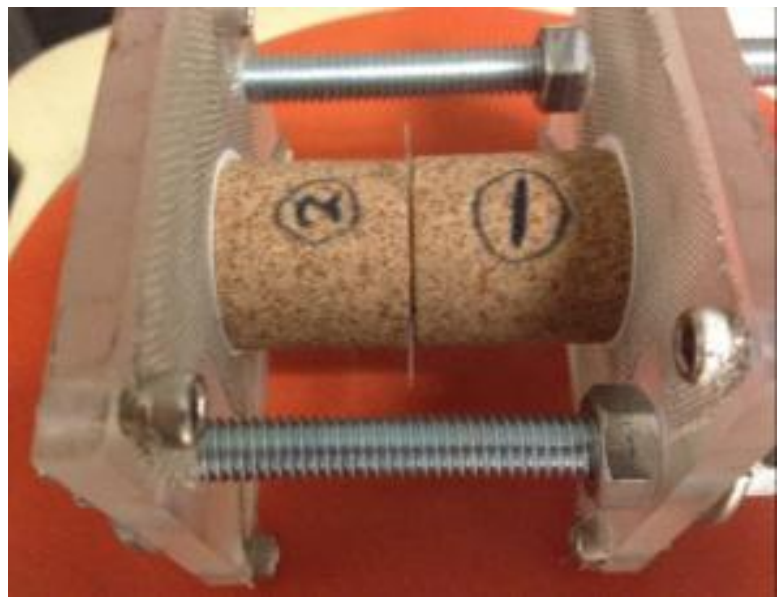

Figure 5: Simulating fracture with different apertures between homogeneous samples s1 and s2 


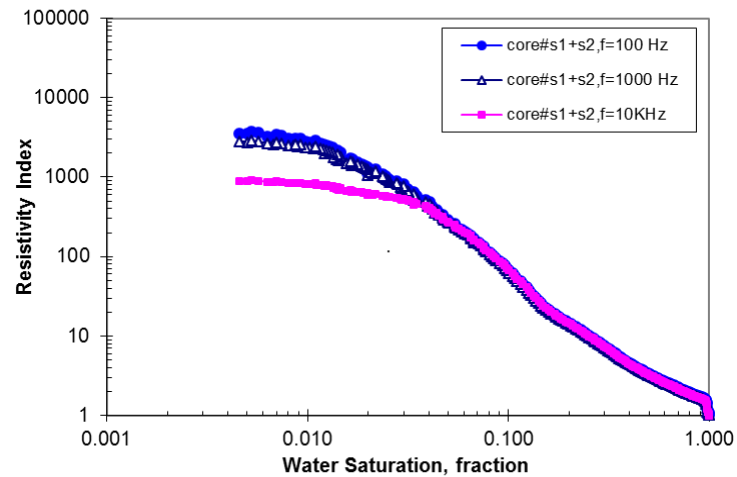

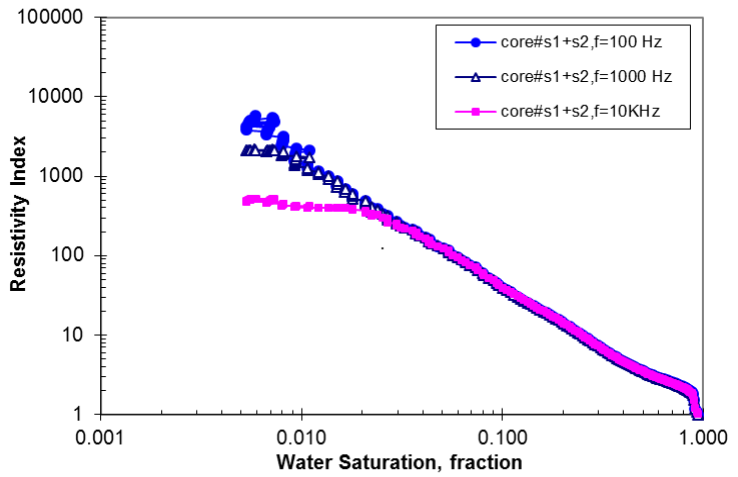

(b) Resistivity Index vs. water saturation

of two samples $s 1$ and $s 2(s 1+$ one film ring $+s 2)$

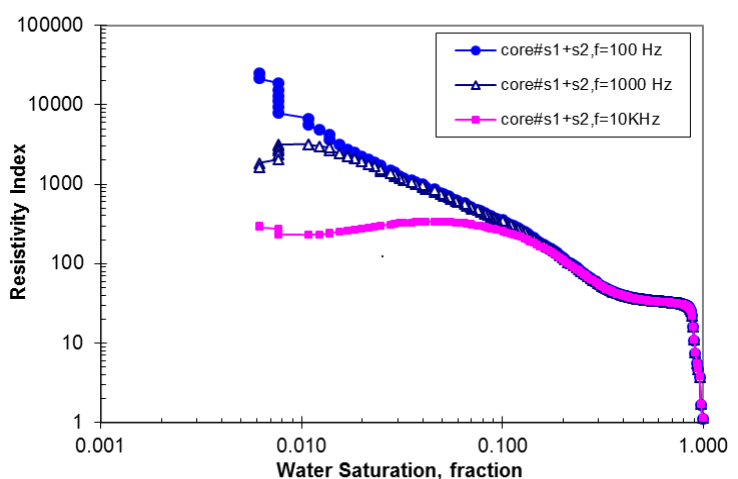

(d) Resistivity Index vs. water saturation

of two samples s1 and $s 2(s 1+3$ film ring $+s 2)$

Figure 6: Resistivity Index vs. time water saturation of two samples s1 and s2

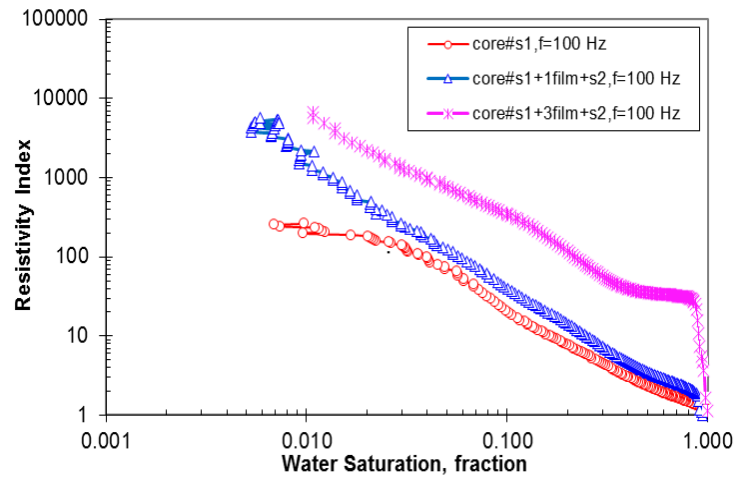

(a) Comparison of resistivity at $100 \mathrm{~Hz}$

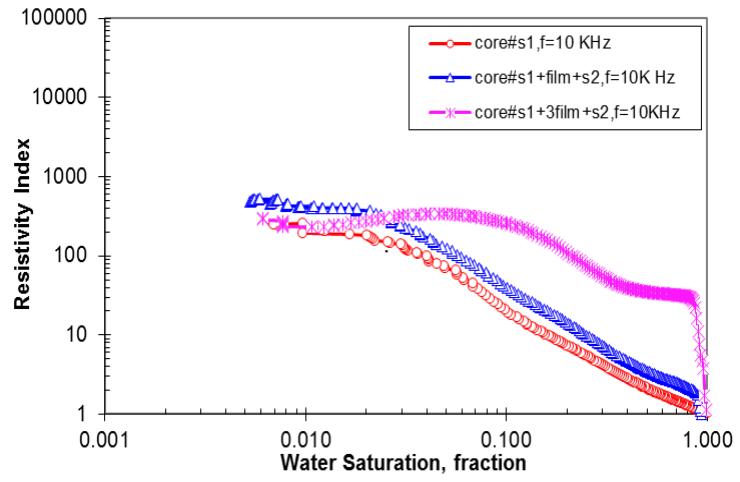

(b) Comparison of resistivity at $10 \mathrm{kHz}$ 

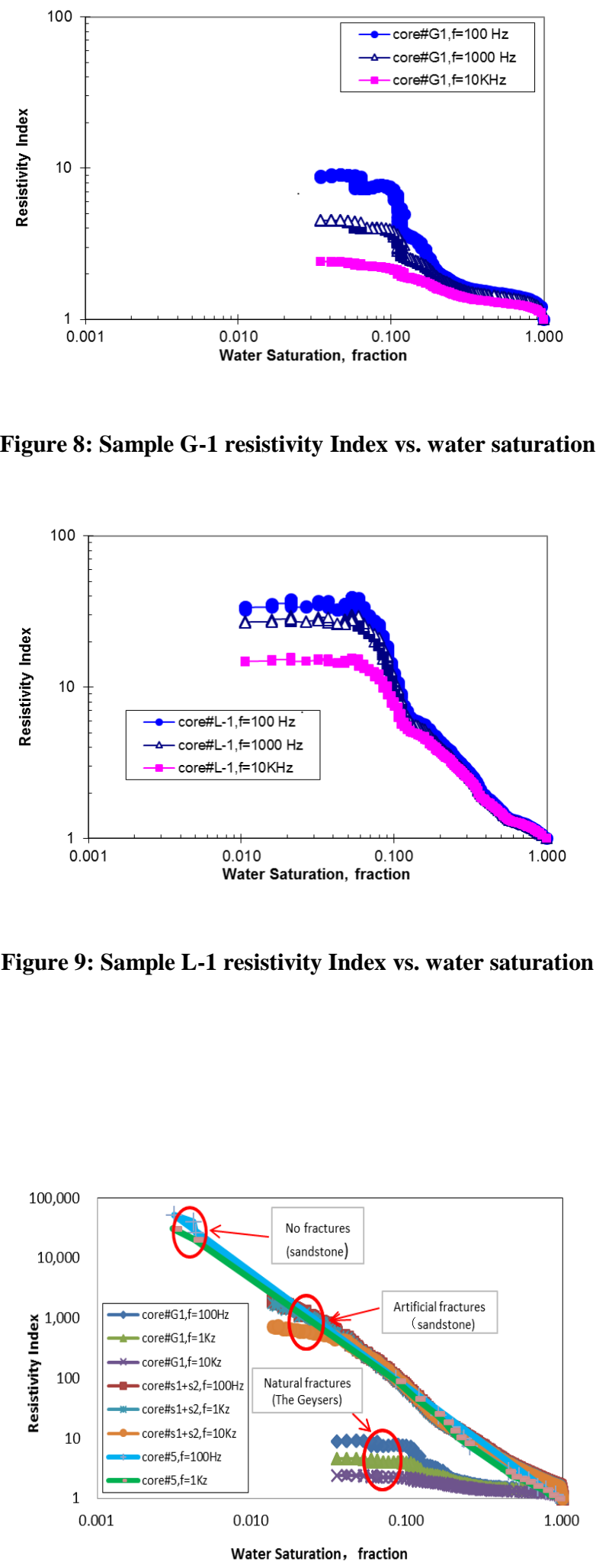


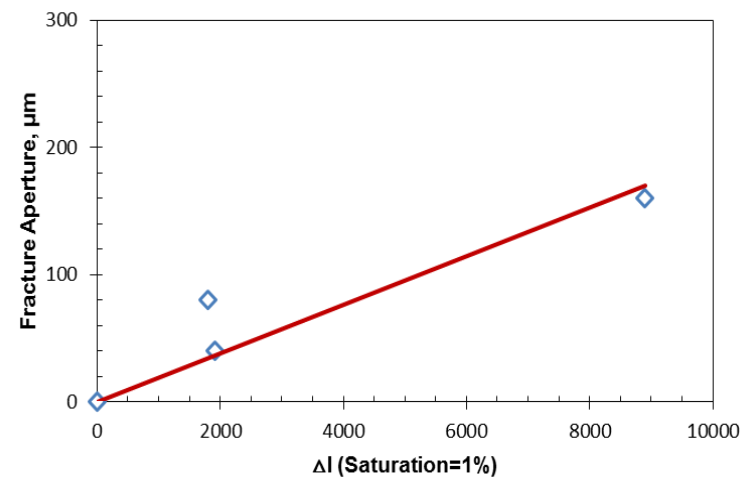

Figure 11: Fracture aperture vs. resistivity index difference in rocks with different types of fractures

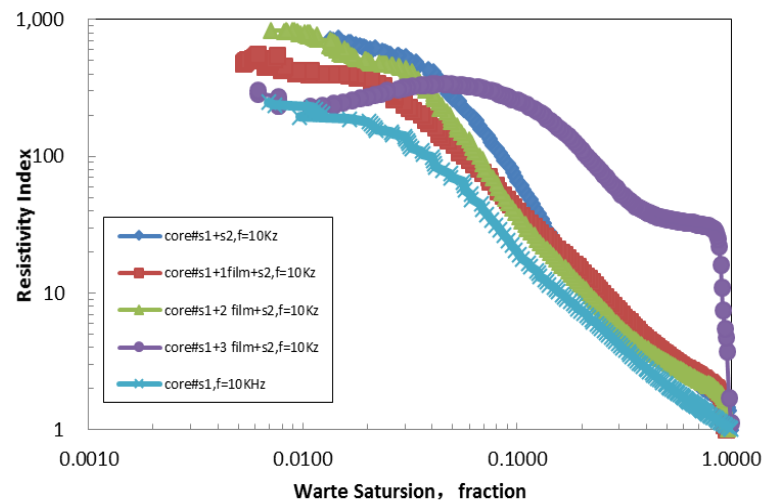

Figure 12: Comparison of resistivity at $10 \mathrm{KHz}$ in the rock system with samples s1 and s2

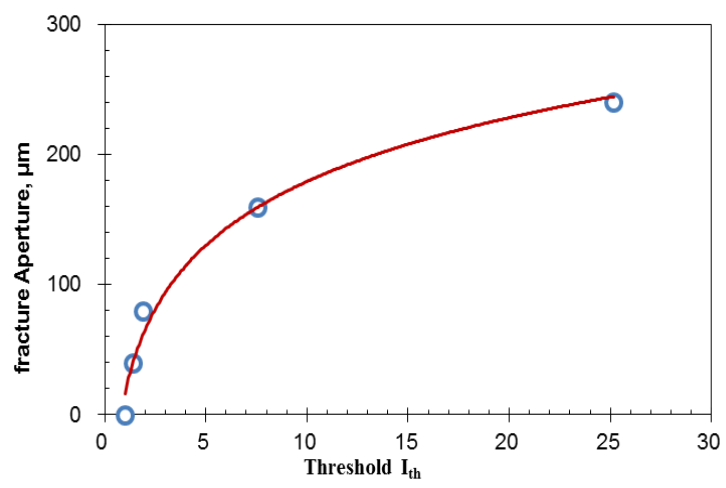

Figure 13: Fracture aperture vs. threshold resistivity index in the system with samples $\mathrm{s} 1$ and s2 (frequency=10 KHz) 